\title{
Transparent Nanocrystallite Silver for Antibacterial Coating
}

\author{
W. Ahliah Ismail, Zainal Abidin Ali, and R. Puteh \\ Corrosion and Coating Laboratory, Physics Department, Universiti Malaya, 50603 Kuala Lumpur, Malaysia \\ Correspondence should be addressed to Zainal Abidin Ali; zaba_87@yahoo.com
}

Received 18 March 2013; Revised 27 May 2013; Accepted 27 May 2013

Academic Editor: William W. Yu

Copyright (C) 2013 W. Ahliah Ismail et al. This is an open access article distributed under the Creative Commons Attribution License, which permits unrestricted use, distribution, and reproduction in any medium, provided the original work is properly cited.

\begin{abstract}
Transparent sol-gel film with antibacterial coating property incorporating silver nanoparticles has been successfully developed. Silver nanoparticles were synthesized by precipitation method at room temperature. XRD structural studies show that crystallite sizes in the range of $18 \mathrm{~nm}$ to $40 \mathrm{~nm}$ were produced. The coating system used methyltrimethoxy silane as binder and N-propanol as diluent to obtain the highest transperancy. $2.5 \%$ wt of nanosilver crystallites was added as antibacterial agent. The coating mixture was applied onto glass plates using sponges and tested against Staphylococcus aureus, Escherichia coli, and Pseudomonas aeruginosa. Values of antimicrobial activity of 4.6, 7.2, and 4.2 were, respectively, obtained for Staphylococcus aureus, Escherichia coli and Pseudomonas Aeruginosa. Coating with antimicrobial activity greater than 2 classified as antibacterial.
\end{abstract}

\section{Introduction}

Antibacterial is an important branch of functional coating that plays an important role not only for general hygiene but also for saving life as disinfectant in places such as operation theatre in hospitals. Antibacterial studies are mostly evolved around Staphylococcus aureus [1], Escherichia coli [2] and Pseudomonas aeruginosa [3]. Staphylococcus aureus is frequently found in human respiratory tract and skin. It is a common cause of skin infections, respiratory disease, and food poisoning. On the other hand, Escherichia coli is commonly found in lower intestine of warm blooded organism. It usually causes the food poisoning and is occasionally responsible for product recalls due to food contamination. The third bacteria Pseudomonas Aeruginosa is considered as one of the toughest bacterial strain and able to survive in harsh environments. It does not usually cause illness to healthy people but it is described as an opportunistic organism causing serious infection when our normal defences system weakened. It represents a great threat to the most vulnerable hospital patients, for example, intensive care patients, those with depleted immune system such as cancer patients, people with serious burn, and premature babies in neonatal units.

There is enormous interest in the research of highly efficient and low-cost antibacterial surface treatments to avoid the breeding and spreading of the harmful microorganisms $[4,5]$. Most of the approaches for achieving antibacterial surfaces are based on silver particles [6-9]. The silver particles provide ions which are highly toxic to bacteria. The advantage of silver as antibacterial agent is the selective toxicity to a wide range of microorganism. Over the years, studies have shown that the miniaturization of silver particles has significantly improved the performance as antibacterial agent $[2,6]$. Nanoparticles with higher specific area are more efficient in releasing silver ions. Sol gel is one of the methods used to incorporate silver nanoparticles in the coating. It has several advantages such as high purity, homogeneity, and low processing temperatures. Since sol is usually applied to the surface by dip coating or spin coating, this limits the application of the coatings to only small size materials or substrates as dip or spin coater is unable to accommodate bigger material. Thus the coater itself becomes a limiting factor in the antibacterial applications.

Therefore in this work, we would like to report the antibacterial behaviour of our transparent coating against Staphylococcus aureus, Escherichia coli, and Pseudomonas aeruginosa, in which the sol was applied using only a sponge. No dip or spin coater was used. The coating has been prepared according to our previous work [10], where the details on the coating properties are available. 
For antibacterial activity measurement, it is a common procedure to carry out the test according to Japanese Industrial Standard, JIS Z 2801. This method was developed to measure the antibacterial activity in hydrophobic materials, originally resulting from the incorporation of silver ions into rigid polymers. Developed by a consortium of workers comprised of manufacturers of silver-based antimicrobial agents, government-based research organisations, and universities under the organisation of the Society of Industrial technology for Antimicrobial Articles (SIAA), the method has then been validated by ring tests within Japan [11] and now forms the basis of a draft ISO standard which is being validated by the SIAA in collaboration with the International Biodeterioration Research Group (IBRG [12]). In JIS Z 2801, the antibacterial activity is measured by quantifying the survival of bacterial cells which have been held in intimate contact for 24 hours at $35^{\circ} \mathrm{C}$ with a surface that contains an antibacterial agent. The antibacterial property is measured by comparing the survival of bacteria on a treated material with that achieved on an untreated material.

\section{Experimental Method}

2.1. Nanosilver Crystal Precipitation. Silver nanocrystals were prepared according to the method reported in [13]. $20 \mathrm{~mL}$ of ethylene diamine was added into the silver nitrate solution and stirred for 5 minutes. Cetyltrimethylammonium bromide (CTAB) was added to the solution as a dispersing agent and stirred vigorously for another 5 minutes before adding hydrazine hydrate. The solution was stirred and kept at the room temperature for 15 minutes. The particles were separated from the solution by centrifuging the solution at $5000 \mathrm{rpm}$ for 20 minutes. The particles were washed from the reactants chemicals by repeating the centrifuging process with deionised water and lastly with ethanol. The particles gathered were dried in desiccators for $24 \mathrm{hrs}$. Ball milling process with weight ratio of ball to sample 120:1 was carried out for 4 hours at $300 \mathrm{rpm}$. The milled particles were characterised using XRD to confirm the crystal structure and estimate the crystallite size.

2.2. Preparation of Coating Mixture for Antibacterial Testing. N-propanol and methyltrimethoxy silane $\left(\mathrm{Si}-\mathrm{CH}_{3}-\right.$ $\left.\left(\mathrm{OCH}_{3}\right)_{3}\right)$ was mixed in a beaker with the ratio of $1: 1.2 .5 \% \mathrm{wt}$ of silver nanocrystal was added into the system and was grinded in the ball mill for $1 \mathrm{hr}$. Nitric acid was diluted to obtain the $\mathrm{pH}$ of 0.1 and was used as catalyst (10\% wt). The coating process was carried out in room temperature of $26^{\circ} \mathrm{C}$ and absolute humidity $30 \%$. These two factors were kept constant throughout the experiment. The dried samples were measured for transparency using haze meter with D65 illumination light at room temperature, and surface quality was evaluated using a microscope with 500x maximum magnification.

2.3. Antibacterial Activity Test. The dried sample was tested against Staphylococcus aureus, Escherichia coli, and Pseudomonas Aeruginosa according to JIS Z 2801:200 (Antimicrobial

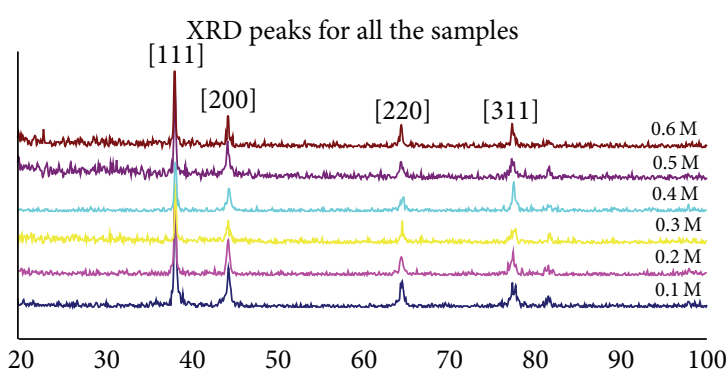

FIGURE 1: XRD pattern of silver particles produced with various silver nitrate molarity.

product: test for antimicrobial activity and efficacy) by an accredited testing lab (SIRIM QAS International Sdn Bhd). This ensures and guarantees reliability, accuracy, and validity of the results.

As reported by [11-13], the test microorganism is prepared by growth in a liquid culture medium. The suspension of test microorganism is standardized by dilution in a nutritive broth (this affords microorganisms the potential to grow during the test). Control and test surfaces are inoculated with $0.4 \mathrm{~mL}$ of the germ suspension in triplicate. Then the inoculum is covered with a film to prevent the evaporation of the suspension and to ensure close contact with the samples surface. Immediately after inoculation, the bacteria from the reference sample are separated from the sample surfaces and the number of viable germs is determined ( $t_{0}$ value) by elution followed by dilution and plating. The other samples $\left(t_{24}\right)$ are allowed to incubate in a humid environment for 24 hours. After incubation, microbial concentrations are determined by elution followed by dilution and plating. Activity/efficacy is calculated by comparing the germ concentration after 24 hours relative to concentration of the blank sample after 24 hours.

\section{Result and Discussion}

3.1. Structural Study and Determination of Crystallite Size. The chemical route for the formation of silver nanoparticles can be described as follows [14]:

$$
\begin{aligned}
& \mathrm{Ag}^{+}+\left(\mathrm{CH}_{2} \mathrm{NH}_{2}\right)_{2} \longrightarrow\left[\mathrm{Ag}\left(\mathrm{CH}_{2} \mathrm{NH}_{2}\right)_{2}\right]^{+} \\
& 4\left[\mathrm{Ag}\left(\mathrm{CH}_{2} \mathrm{NH}_{2}\right)_{2}\right]^{+}+5 \mathrm{~N}_{2} \mathrm{H}_{4} \\
& \longrightarrow 4 \mathrm{Ag}+4 \mathrm{~N}_{2} \mathrm{H}_{5}+\mathrm{N}_{2}+4\left(\mathrm{CH}_{2} \mathrm{NH}_{2}\right)
\end{aligned}
$$

In (1), the first reaction of $\mathrm{Ag}^{+}$with the ethylenediamine is to form the $\left[\mathrm{Ag}\left(\mathrm{CH}_{2} \mathrm{NH}_{2}\right)_{2}\right]^{+}$complex and the following reaction in (2) with the hydrazine hydrate to form silver metal. CTAB was added to disperse the particles formed. The silver precipitate produced was structurally analysed by XRD from $5^{\circ}$ to $90^{\circ} 2 \theta$ angle (Figure 1 ). The same peaks appeared in all of the samples and after fitting, and it is confirmed that the crystal consists of silver atoms only. There was no evidence of oxygen or other atoms existed in the crystal structure. The crystals formed are face-centered cubic structure. 
TABLE 1: The antibacterial efficacy against Pseudomonas aeruginosa, Escherichia coli, and Staphylococcus aureus.

\begin{tabular}{lcccc}
\hline Bacteria species & Sample & $\begin{array}{c}\text { Number of viable cells of } \\
\text { bacteria at } 0 \mathrm{hr}\end{array}$ & $\begin{array}{c}\text { Number of viable cells of } \\
\text { bacteria after 24 hrs }\end{array}$ & $\begin{array}{c}\text { Value of antimicrobial } \\
\text { activity }\end{array}$ \\
\hline Pseudomonas aeruginosa & $2.5 \%$ silver coating* & $1.8 \times 10^{5}$ & $2.0 \times 10^{2}$ & 4.6 \\
& Control** $^{*}$ & $1.9 \times 10^{5}$ & $9.5 \times 10^{6}$ & - \\
Escherichia coli & $2.5 \%$ silver coating & $4.0 \times 10^{5}$ & $<10$ & 7.2 \\
& Control & $4.4 \times 10^{5}$ & $1.7 \times 10^{8}$ & - \\
Staphylococcus aureus & $2.5 \%$ silver coating & $2.0 \times 10^{5}$ & $8.9 \times 10^{2}$ & 4.2 \\
& Control & $2.0 \times 10^{5}$ & $1.5 \times 10^{7}$ & - \\
\hline
\end{tabular}

${ }^{*} 2.5 \%$ silver coating: coating consists of silver and sol-gel formulation.

${ }^{* *}$ Control: glass slides with no coating applied.

TABLE 2: The antibacterial tests against Pseudomonas aeruginosa, Escherichia coli, and Staphylococcus aureus on glass slides that were coated only with sol gel, without any Ag nanoparticles.

\begin{tabular}{lcccc}
\hline Bacteria species & Sample & $\begin{array}{c}\text { Number of viable cells of } \\
\text { bacteria at } 0 \mathrm{hr}\end{array}$ & $\begin{array}{c}\text { Number of viable cells of } \\
\text { bacteria after 24 hrs }\end{array}$ & $\begin{array}{c}\text { Value of antimicrobial } \\
\text { activity }\end{array}$ \\
\hline \multirow{2}{*}{ Pseudomonas aeruginosa } & Sol-gel-coated slide* & $2.0 \times 10^{5}$ & $3.6 \times 10^{7}$ & - \\
& Control $^{* *}$ & $1.9 \times 10^{5}$ & $9.5 \times 10^{6}$ & - \\
Escherichia coli & Sol-gel-coated slide & $4.6 \times 10^{5}$ & $1.1 \times 10^{8}$ & - \\
& Control & $4.0 \times 10^{5}$ & $1.7 \times 10^{8}$ & - \\
Staphylococcus aureus & Sol-gel-coated slide & $2.0 \times 10^{5}$ & $1.5 \times 10^{7}$ & - \\
& Control & $2.0 \times 10^{5}$ & $1.5 \times 10^{7}$ & - \\
\hline
\end{tabular}

${ }^{*}$ Sol-gel-coated slide: coating consists only sol gel; no Ag silver.

${ }^{* *}$ Control: glass slides with no coating applied.

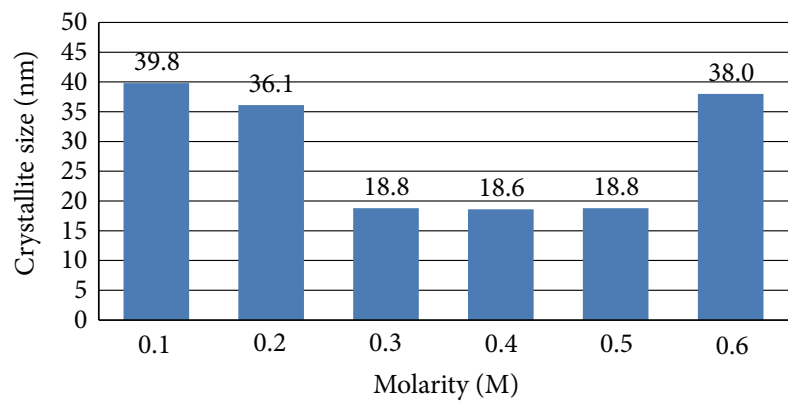

FIGURE 2: Variation of crystallite size with silver nitrate molarity.

Estimation of silver crystallite size was made through Lorentzian curve fit to the strongest peak in the XRD pattern $\mathrm{Ag}$ [111] which is from $37^{\circ}$ to $42^{\circ}$. XRD testing was repeated for all the samples zoomed in at the angle of $2 \theta$ from $37^{\circ}$ to $42^{\circ}$. $\beta$ and $\theta$ of every sample were determined from the peak, and through Scherrer Equation the crystallite size of the samples was calculated and shown in Figure 2.

From Figure 2, it clearly shows that at the molarity of $0.3 \mathrm{M}$ to $0.5 \mathrm{M}$ the crystallite size was the smallest. Size of the silver crystals formed is one of the most important factors in determining the antibacterial efficiency of the silver to fight the microbes. This is attributed to the high surface area to volume ratio and the quantum confinement effect caused by extremely reduced size (i.e., electron confinement in a small area) [15]. The nanocrystallite silver that was synthesised from $0.3 \mathrm{M}$ was then used for the antibacterial testing.
3.2. Antibacterial Test Result. Figure 3 shows three glass surfaces that have been applied with the antibacterial coating. Slide A was the uncoated glass whereas slide B and C both were coated with $2.5 \%$ and $3.5 \%$ of Ag. The coating was transparent. The presence of Ag nanoparticles powder is visible on the surface when the slides were tilted to a certain angle (Figure 3(b)). As has been reported [12], the haze value for $2.5 \%$ was 3.42 .

Figure 4 compares the transparency of the slides optically. The transparency level decreases as the amount of $\mathrm{Ag}$ increases from $2.5 \%$ to $3.5 \%$. As the coating was purposely developed for surface treatment, it should cause only minimal effect to the applied surface in term of colour and level of haziness.

The results for antibacterial test against Staphylococcus aureus, Escherichia coli and Pseudomonas Aeruginosa according to JIS Z 2801 (antimicrobial product test for antimicrobial activity and efficacy) of the coating are shown in Table 1.

Coating with antimicrobial activity greater than 2 is classified as antibacterial. The antibacterial test result clearly shows value of antimicrobial activity of 4.6 for Pseudomonas Aeruginosa, 7.2 for Escherichia coli, and 4.2 for Staphylococcus aureus. All the values exceeded that of value 2 which confirmed the antibacterial coating and therefore comply with the standard of JIS Z 2801.

In order to verify that the antibacterial properties come only from the Ag nanoparticles and not from the sol-gel formulation, we carried out antibacterial tests to slides coated with only the sol gel (no Ag nanoparticles were used). The noncoated slides were used as controls. The results in Table 2 


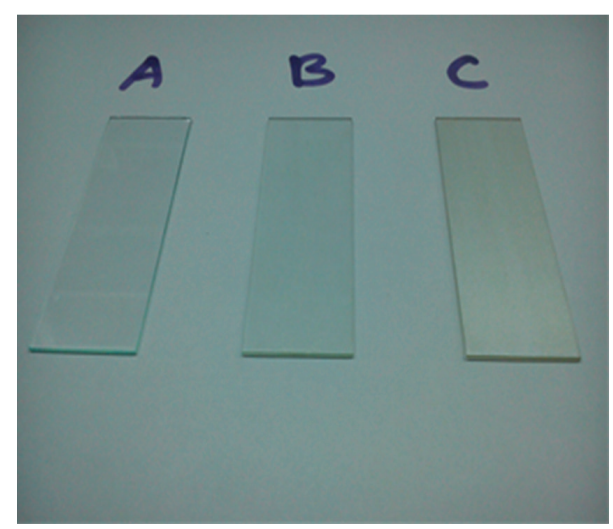

(a)

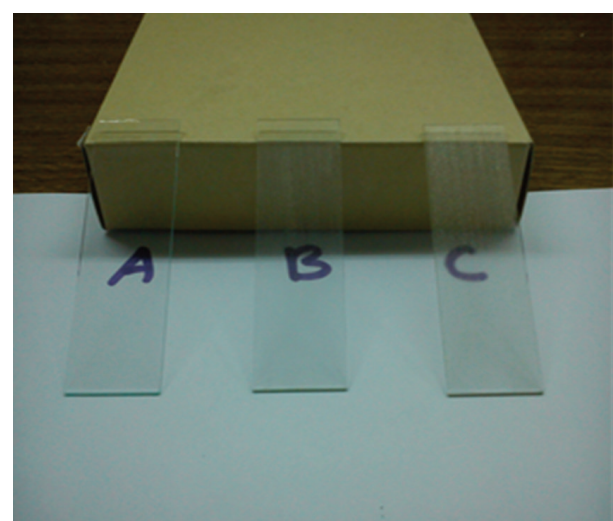

(b)

FIGURE 3: A transparent antibacterial coating applied onto a glass surface; (a) and (b) slide-A-uncoated surface, slide-B-Ag 2.5\%-coated surface, and slide-C-Ag 3.5\%-coated surface.

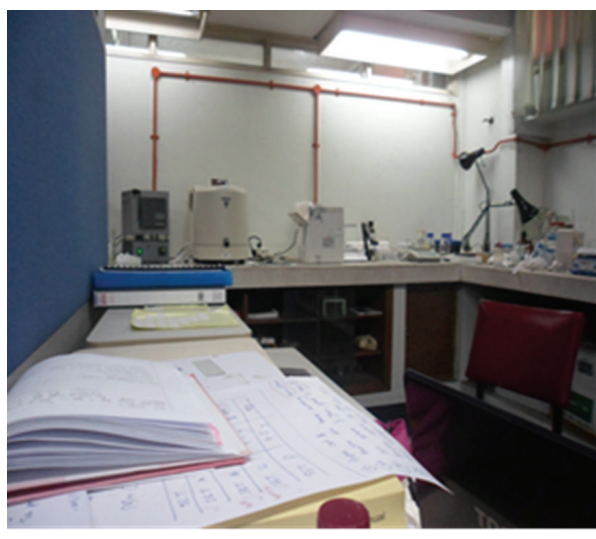

(a)

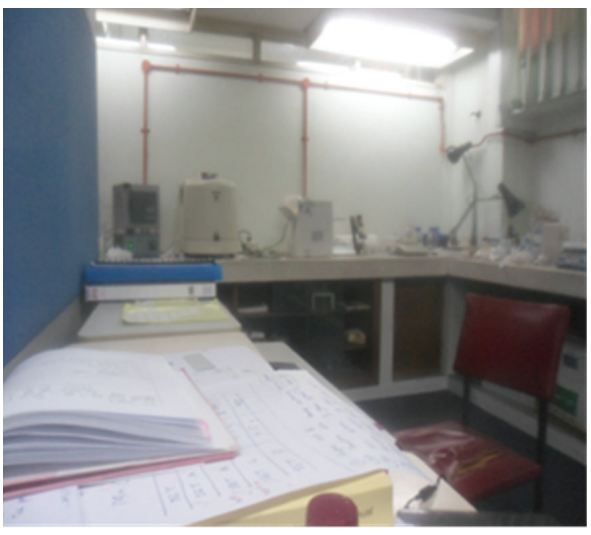

(b)

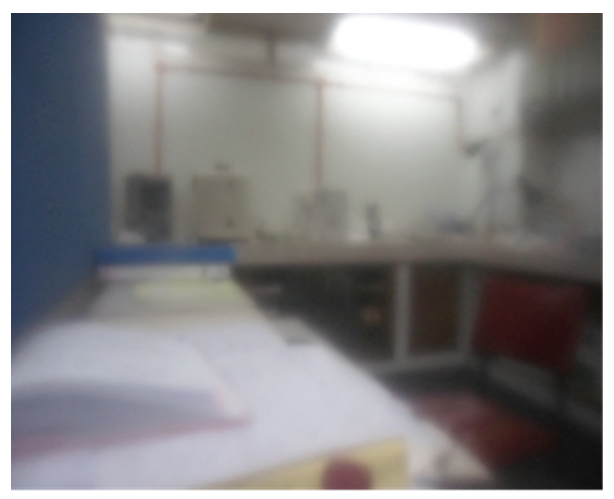

(c)

FIGURE 4: Optical comparison of transparency level by placing the slides approximately $2 \mathrm{~cm}$ in front of the lense of digital camera; (a) slide A-noncoated, (b) slide B-2.5\% Ag, and (c) slide C-3.5\% Ag.

show that the number of bacterial is increased after 24 hours for all types of bacteria for the sol-gel-coated slides. This verifies and proves that the sol gel does not kill and thus has no antibacterial properties.

Antibacterial nanocrystallite silver may work in two ways; firstly, it breaks through the permeability of outer membrane, resulting in the leakage of cellular materials. It is well known that bacteria possess an outer membrane to serve as a selective permeability barrier which protects bacteria from harmful agents, such as detergents, drugs, toxins, and degradative enzymes, and penetrating nutrients to sustain bacterial growth. Kim et al. [16] reported studies based on $S$. aureus and $E$. coli that the free radicals could induce bacterial cell membrane damage by enhancing the permeability of 
the membrane. The bacteria will then undergo a protein leakage as a result of the increasing membrane permeability.

Secondly, as a result of the increasing permeability nanocrystallite silver can enter the inner membrane and inactivate respiratory chain dehydrogenases, thus inhibiting respiration and growth of cells. Holt and Bard proved this by showing that $\mathrm{Ag}^{+}$can inhibit the respiration of $E$. coli by determining change of oxygen dissolved in culture resolution [17]. A report [18] on Pseudomonas aeruginosa also suggested that silver nanoparticles not only inhibited the growth but also the ability of the organism to synthesize the exopolysaccharide. The exopolysaccharide functions not only to protect the bacteria from the host defense mechanism but also mediate the adhesion of the organism to the surface. At the same time, the silver could as well affect some proteins and phosphate lipids and induce collapse of membrane, resulting in cell decomposition and death eventually. This is supported by Kim et al. [19] who found that $\mathrm{Ag}^{+}$interacted with thiol (-SH) group of cysteine by replacing the hydrogen atom to form -S$\mathrm{Ag}$, thus hindering the enzymatic function of affected protein to inhibit growth of E. coli.

The most attractive aspects of this work are the simplicity of the coating method and its effectiveness in killing the bacteria. As has been reported, the coating was applied using only a melamine sponge which means that everybody could use it. No special expertise is required. Moreover, it would provide a simple and cheaper way for medical rooms and facilities (e.g., wall, floor, and table) to be bacterial-free environment anytime required.

\section{Conclusion}

We managed to develop an antimicrobial coating layer that is very easy to apply and dry in the room temperature. The coating is very transparent, clear, and will not change the original property of the substrate. It is very suitable for the window glasses, wall, and floor coating. The best formulation was obtained from formulation $1: 1$ ratio of methyltrimethoxy silane to N-propanol. The coating shows the antibacterial activity to gram-positive (Pseudomonas Aeruginosa and Escherichia coli) and gram-negative (Staphylococcus aureus) bacteria strain.

\section{Acknowledgment}

The authors are thankful to University of Malaya and Fundamental Research Grant Scheme (FRGS)-FP 054-2010B for providing the necessary facilities and funding for this research.

\section{References}

[1] W.-R. Li, X.-B. Xie, Q.-S. Shi, S.-S. Duan, Y.-S. Ouyang, and Y.-B. Chen, "Antibacterial effect of silver nanoparticles on Staphylococcus aureus," BioMetals, vol. 24, no. 1, pp. 135-141, 2011.

[2] W.-R. Li, X.-B. Xie, Q.-S. Shi, H.-Y. Zeng, Y.-S. Ou-Yang, and Y.-B. Chen, "Antibacterial activity and mechanism of silver nanoparticles on Escherichia coli," Applied Microbiology and Biotechnology, vol. 85, no. 4, pp. 1115-1122, 2010.

[3] S. S. Birla, V. V. Tiwari, A. K. Gade, A. P. Ingle, A. P. Yadav, and M. K. Rai, "Fabrication of silver nanoparticles by Phoma glomerata and its combined effect against Escherichia coli, Pseudomonas aeruginosa and Staphylococcus aureus," Letters in Applied Microbiology, vol. 48, no. 2, pp. 173-179, 2009.

[4] P. Pallavicini, A. Taglietti, G. Dacarro et al., "Self-assembled monolayers of silver nanoparticles firmly grafted on glass surfaces: Low Ag+ release for an efficient antibacterial activity," Journal of Colloid and Interface Science, vol. 350, no. 1, pp. 110$116,2010$.

[5] H. Oveisi, S. Rahighi, X. Jiang et al., "Unusual antibacterial property of mesoporous titania films: drastic improvement by controlling surface area and crystallinity," Chemistry, vol. 5, no. 9, pp. 1978-1983, 2010.

[6] C. Marambio-Jones and E. M. V. Hoek, "A review of the antibacterial effects of silver nanomaterials and potential implications for human health and the environment," Journal of Nanoparticle Research, vol. 12, no. 5, pp. 1531-1551, 2010.

[7] M. Gladitz, S. Reinentnn, and H.-J. Radusch, "Preparation of silver nanoparticle dispersions via a dendritic-polymer template approach and their use for antibacterial surface treatment," Macromolecular Materials and Engineering, vol. 294, no. 3, pp. 178-189, 2009.

[8] L. Ploux, M. Mateescu, K. Anselme, and K. Vasilev, "Antibacterial properties of silver-loaded plasma polymer coatings," Journal of Nanomaterials, vol. 2012, Article ID 674145, 9 pages, 2012.

[9] W. Li, "Antibacterial coating incorporating silver nanoparticles by microarc oxidation and ion implantation," Journal of Nanomaterials, vol. 2013, Article ID 542878, 8 pages, 2013.

[10] W. A. Ismail, Z. A. Ali, and R. Puteh, "Optical and physical properties of methyltrimethoxysilane transparent film incorporated with nanoparticles," Advances in Materials Science and Engineering, vol. 2012, Article ID 124820, 6 pages, 2012.

[11] S. Suzuki, S. Imai, and H. Kourai, "Background and evidence leading to the establishment of the JIS standard for antimicrobial products," Biocontrol Science, vol. 11, no. 3, pp. 135-145, 2006.

[12] S. Imai, The Development of an ISO Standard for Measureing the Antibacterial Activity of Surfaces, Hygienic Coatings and Surfaces, Paris, France, 2005.

[13] ISO 22196, QualityLabs. N.p., n.d. Web, May 2013.

[14] J.-K. Liu, X.-H. Yang, and X.-G. Tian, "Preparation of silver/ hydroxyapatite nanocomposite spheres," Powder Technology, vol. 184, no. 1, pp. 21-24, 2008.

[15] Q. Li, S. Mahendra, D. Y. Lyon et al., "Antimicrobial nanomaterials for water disinfection and microbial control: potential applications and implications," Water Research, vol. 42, no. 18, pp. 4591-4602, 2008.

[16] S.-H. Kim, H.-S. Lee, D.-S. Ryu, S.-J. Choi, and D.-S. Lee, "Antibacterial activity of silver-nanoparticles against Staphylococcus aureus and Escherichia coli," Korean Journal of Microbiology and Biotechnology, vol. 39, no. 1, pp. 77-85, 2011.

[17] K. B. Holt and A. J. Bard, "Interaction of silver(I) ions with the respiratory chain of Escherichia coli: an electrochemical and scanning electrochemical microscopy study of the antimicrobial mechanism of micromolar Ag," Biochemistry, vol. 44, no. 39, pp. 13214-13223, 2005. 
[18] K. Kalishwaralal, S. BarathManiKanth, S. R. K. Pandian, V. Deepak, and S. Gurunathan, "Silver nanoparticles impede the biofilm formation by Pseudomonas aeruginosa and Staphylococcus epidermidis," Colloids and Surfaces B, vol. 79, no. 2, pp. 340-344, 2010.

[19] J. Y. Kim, C. Lee, M. Cho, and J. Yoon, "Enhanced inactivation of E. coli and MS-2 phage by silver ions combined with UV-A and visible light irradiation," Water Research, vol. 42, no. 1-2, pp. 356-362, 2008. 

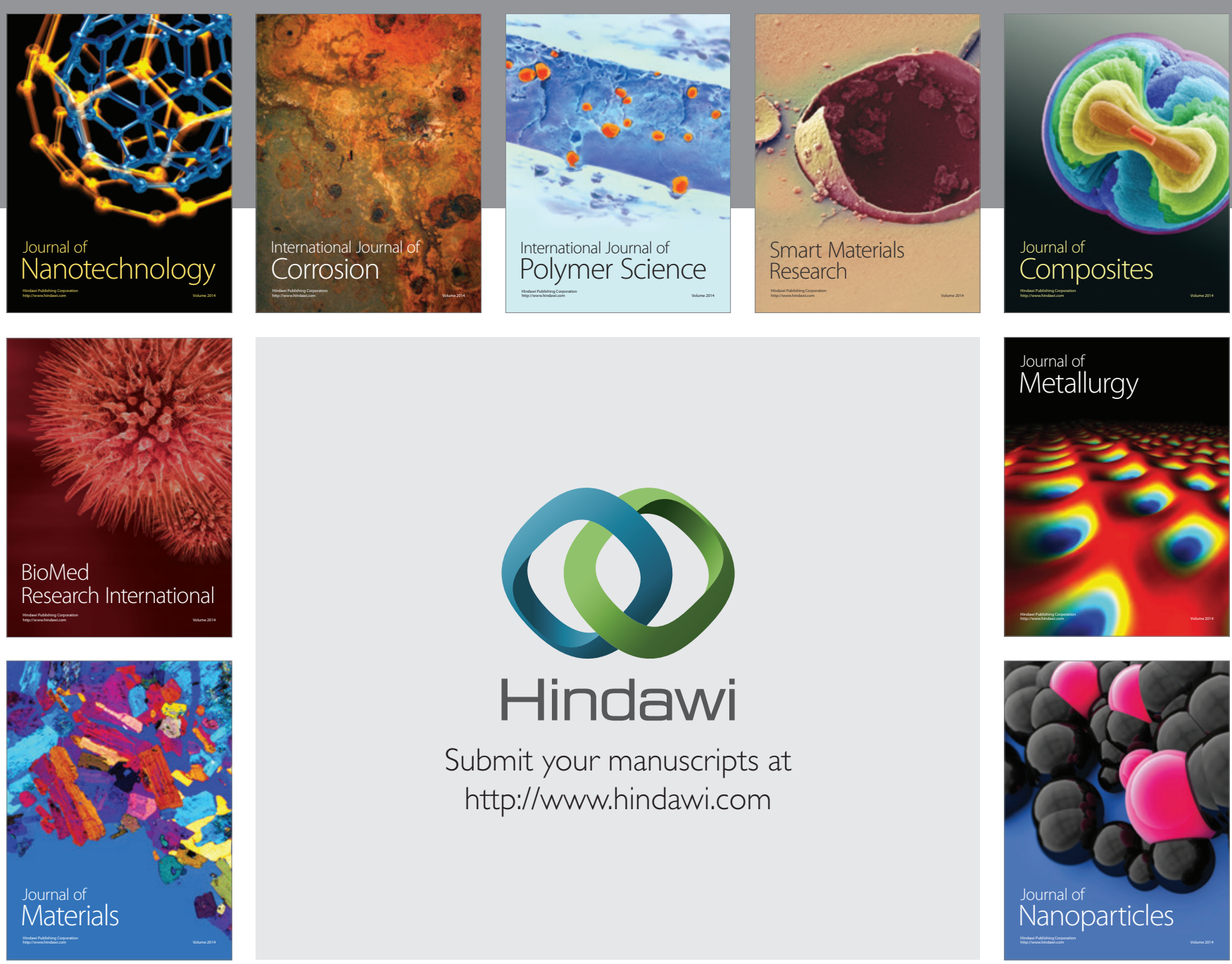

Submit your manuscripts at http://www.hindawi.com
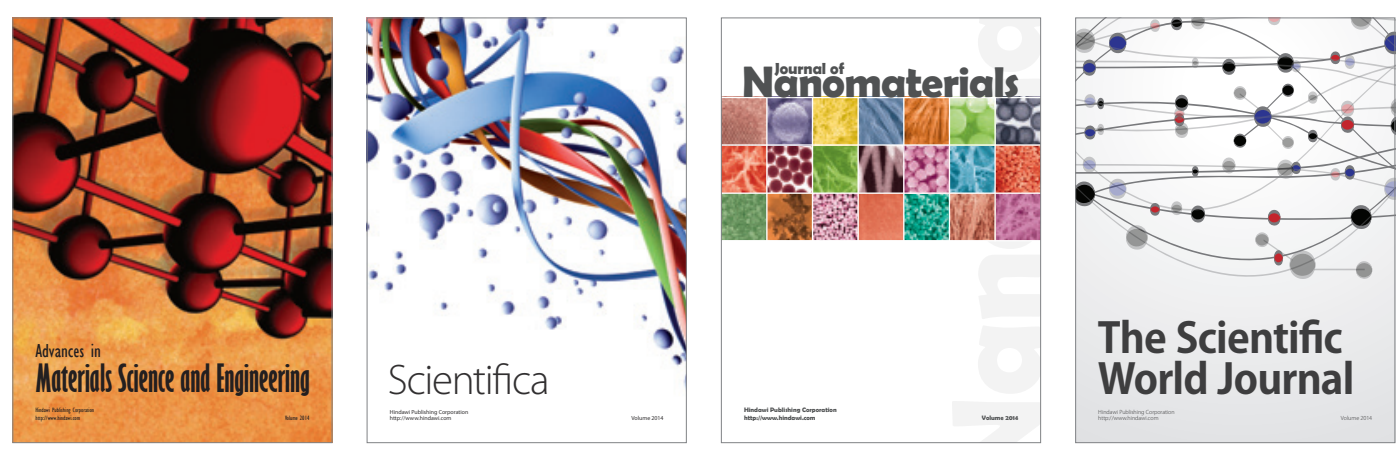

\section{The Scientific World Journal}
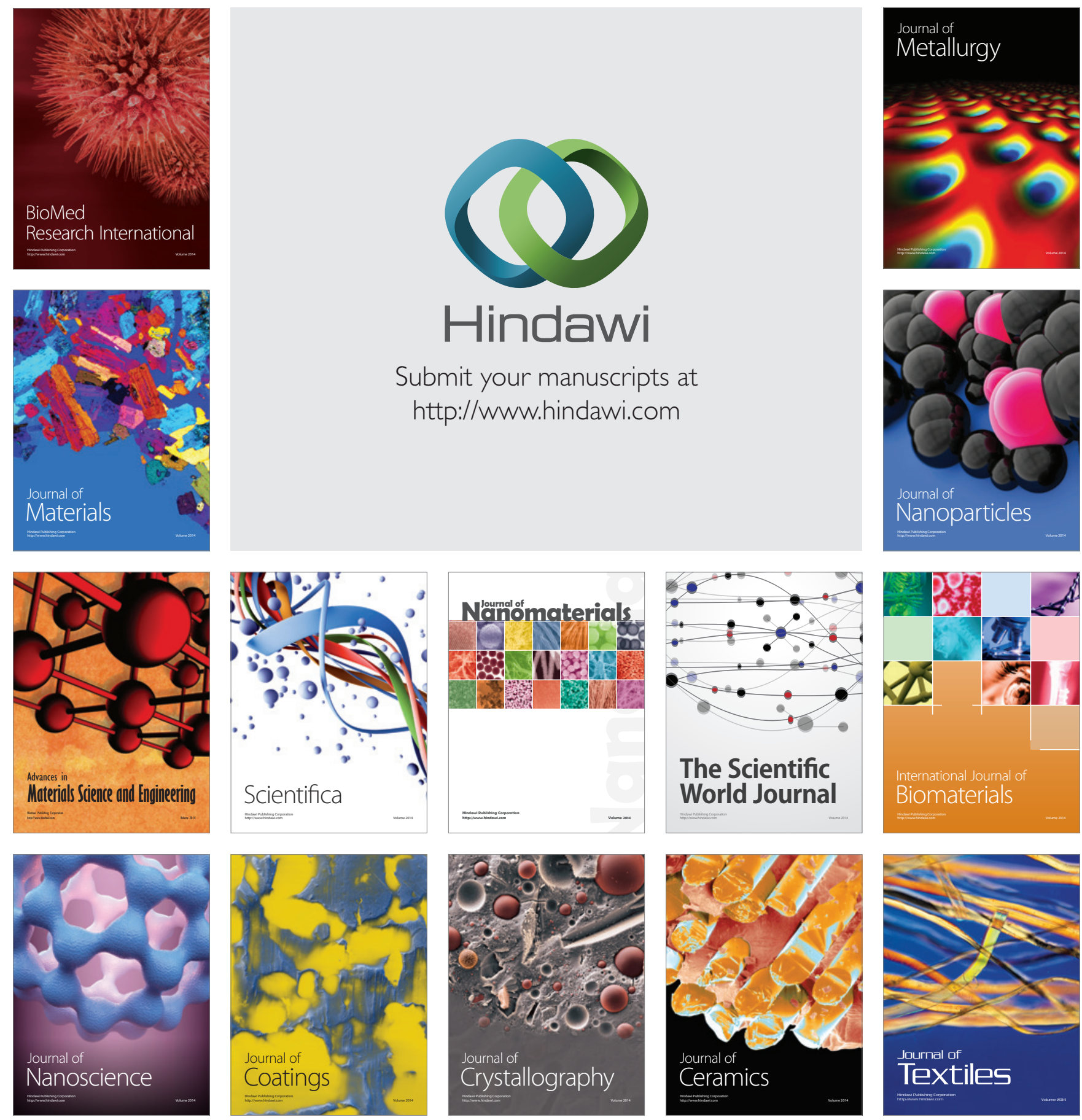